\title{
Simultaneous Removal of Nutrients by Geopolymers made from Industrial By-Products
}

\author{
Tatiana Samarina, Esther Takaluoma \\ Kajaani University of Applied Sciences \\ Ketunpolku 1, PL 52, FI-87101, Kajaani, Finland \\ tatiana.samarina@kamk.fi; esther.takaluoma@kamk.fi
}

\begin{abstract}
An effective way to recover phosphate and ammonium from contaminated waters is of great demand. Nutrients can be reused and applied to land as valuable fertilizers. Composite adsorbents were prepared from industrial waste materials and calcined natural clay. The ability of the new adsorbents to simultaneously remove phosphate and ammonium from diluted solutions was evaluated. Paper mill sludge or blast furnace slag together with kaolinite clay were used as raw materials to produce inorganic polymers by alkaline activation. All raw materials and composites have been characterized by XRF and XRD. The influence of clay and waste material in the adsorbent composition, the adsorbent dose, and time of adsorption characteristics have been investigated at static conditions by bench-top tests. For the best identified composition (metakaolin and blast furnace slag composite), the phosphate adsorption increases from 0.05 mg-P/g for pure clay up to $8.5 \mathrm{mg}-\mathrm{P} / \mathrm{g}$ for composite with blast furnace slag content of $60 \mathrm{wt} \%$, while a decrease on the ammonium sorption capacity from $15 \mathrm{mg}-\mathrm{N} / \mathrm{g}$ to $7 \mathrm{mg}-\mathrm{N} / \mathrm{g}$ is observed. Phosphate removal was enhanced when ammonium was present, while ammonium removal was slightly varied whether phosphate ions in the system or not. In case of ammonium, ion exchange is the likely mechanism of removal, whereas in the case of phosphate surface precipitation in form of hydroxyapatite appears to occur.
\end{abstract}

Keywords: Adsorption, Geopolymer composite, Metakaolin, Ammonium removal, Phosphate removal, Wastewater treatment, Circular economy, Nutrient recovery.

\section{Introduction}

Nutrient discharge has been linked to eutrophication of receiving waters, and major sources of phosphorus and nitrogen in the aquatic ecosystems are from human activity (mostly agriculture and urban) [1]. Therefore, the simultaneous removal and capture of both nutrients (phosphate and ammonium) from contaminated diluted waters is an interesting challenge since their chemical properties vary considerably.

Zeolites and other alumino-silicate materials have been reported as valuable adsorptive media to remove ammonium from municipal and industrial wastewater [2], [3]. However, these materials were rarely used for simultaneous phosphate and ammonium sorption due to their low capacities towards phosphate ions. Lately, zeolites modified by a hydrated aluminum [4] or calcium ions [5] have shown promising results for simultaneous nutrient removal. The capacity enlargement of these adsorbents towards phosphate is limited by surface modification. To overcome this limitation, structural changes could be made to prevent substantial loss of capacity for ammonium and save high adsorption potential of adsorbents for phosphate.

Lately, new adsorbents for ammonium removal with maximum capacity up to $21 \mathrm{mg} \mathrm{NH} / \mathrm{g}$ was produced by alkali activation [6]. The bench-top and small-scale piloting tests done on landfill leachate and municipal wastewater after primary treatment have shown a satisfactory removal rate [7], and those materials have been suggested as an alternative to conventional adsorbents due to quality consistency and low price of production. On the other hand, a wide range of industrial by-products could be converted to inorganic polymers containing specified functions by the same geopolymerization technique.

In this study, for the first time composite geopolymer materials are designed and applied for simultaneous removal of phosphate and ammonium ions from diluted solutions. The aims of this work are to synthesize composites with different clay : waste material ratios, to characterize the obtained composites, and to study the influence of some experimental parameters (initial ion concentrations, their mutual presence, adsorbent dose and time) on removal capacities of geopolymer composites. 


\section{Materials and methods}

\subsection{Materials}

Ammonium chloride, phosphoric acid (85\%), sodium hydroxide were purchased from VWR Chemicals. Sodium silicate - ZEOPOL 25 (42-46\%, molar ratio $\mathrm{SiO}_{2}: \mathrm{Na}_{2} \mathrm{O}$ is 2.4-2.6) was purchased from JV Huber. Ammonium chloride was dried at $105^{\circ} \mathrm{C}$ for $2 \mathrm{~h}$ prior to use. The paper mill sludge $(\mathbf{F S})$ was preliminarily dried at room temperature for several days, then the fibre particles contained in the sludge were ignited at $750^{\circ} \mathrm{C}$ for several hours. Kaolinite clay was obtained from Aquaminerals Finland $\mathrm{Oy}$ and calcined at $750^{\circ} \mathrm{C}$ for three hours to obtain metakaolin (MK). Blast furnace slag (BFS) was obtained from Finnsementti Oy in form of fine powder and used as received.

\subsection{Geopolymer composite preparation}

Bulk geopolymers were prepared by mixing $100 \mathrm{~g}$ of solid material (BFS, FS or their mixtures with MK) with alkaline activator in a solid to liquid ratio $(\mathrm{S} / \mathrm{L})$ of 1.1. Alkaline activator contained 6-12 M sodium hydroxide and sodium silicate in a weight ratio of 1.2. The mixtures were allowed to consolidate at ambient temperature for three days, and the concrete-like monolith crushed with a jaw crasher, sieved, and washed with deionized water until pH 7.8. Fraction with particle size of 63-125 $\mu \mathrm{m}$ was used for batch adsorption experiments.

Modifications of geopolymer preparation included $\mathrm{NaOH}$ molarity, type of raw material, and ratio of solid components. Thus, the code of composite 8BFSMK6040 means that this particular geopolymer was prepared with $8 \mathrm{M} \mathrm{NaOH}$, solid material contained $60 \mathrm{wt} \%$ BFS and $40 \mathrm{wt} \% \mathrm{MK}$, respectively. Boundary conditions of synthetic procedure are listed in Table 1.

Table 1: Variation of a geopolymer synthetic procedure and parameters tested in preliminary experiment (adsorbent dose $2 \mathrm{~g} / \mathrm{L}$, contact time $24 \mathrm{~h}$ ).

\begin{tabular}{|l|c|c|}
\hline \multicolumn{1}{|c|}{ Composite } & FSMK & BFSMK \\
Parameter & $6-12 \mathrm{M}$ & $6-12 \mathrm{M}$ \\
\hline NaOH molarity & $20-80$ & - \\
\hline MK/FS ratio, wt $\%$ & - & $20-80$ \\
\hline MK/BFS ratio, wt $\%$ & 10 and $250 \mathrm{mg} \mathrm{L}^{-1}$ & 10 and $250 \mathrm{mg} \mathrm{L}^{-1}$ \\
\hline phosphate removal & $50 \mathrm{mg} \mathrm{L}^{-1}$ & $50 \mathrm{mg} \mathrm{L}^{-1}$ \\
\hline ammonium removal & &
\end{tabular}

\subsection{Material characterisation}

The elemental composition of samples was measured semiquantitatively with an X-ray fluorescence (XRF) spectrometer (PanAnalytical Minipal 4). XRD patterns in geopolymer composites were identified by powder X-ray diffraction (XRD) using a PANnalytical X'Pert PRO MPD diffractometer (Co K $\alpha$ radiations generated at $40 \mathrm{kV}$ and $40 \mathrm{~mA}$, step width of by $0.02^{\circ}$, Highscore software 3.0).

\subsection{Adsorption experiment}

The adsorption experiments were performed using batch equilibration method. In the batch method, a portion of adsorbent $\left(1 \mathrm{~g} \mathrm{~L}^{-1}-10 \mathrm{~g} \mathrm{~L}^{-1}\right)$ was agitated with $200 \mathrm{ml}$ solution contained nitrogen as ammonium, phosphorous as phosphate, or both ions at $30 \mathrm{rpm}$ (overhead shaker) at room temperature for the desired time period to reach equilibrium. The effect of adsorbent dose (initial ion concentration, contact time) on removal of each ion was studied by keeping other factors as constant. After filtration though paper filter (pore diameter $2.5 \mu \mathrm{m}$ ), ammonium concentration were determined according EPA Method 350.3 by an ion-selective electrode, and phosphate concentration were determined according EPA Method 365.3 by UV-Vis spectrophotometry. 


\section{Results and discussion}

Preliminary tests have been carried out prior to the main adsorption experiment section in order to verify the aptitude of composite mixtures to consolidate and form solid geopolymers. Alkaline activators with molarity of sodium hydroxide varying from $6 \mathrm{M}$ to $12 \mathrm{M}$ were used. The ability of the composite to adsorb phosphate and ammonium ions was investigated. The compositions with the highest capacities towards simultaneous phosphate and ammonium ions were selected and used for further examination. Generally, composites prepared using sodium hydroxide with molarity 8M and 10M had higher adsorption characteristics towards both nutrients, although, a tendency to lower ammonium removal has been observed when molarity of activator increase from 6M to $12 \mathrm{M}$. Based on the preliminary results, the geopolymer composites 8BFSMK6040 and 8FSMK2080 were chosen for further bench-top tests, since they were able to reduce the phosphate content by $60 \%$ and ammonium content by $15 \%$ at initial phosphate concentration $10 \mathrm{mg} \mathrm{L}^{-1}$ and ammonium concentration $50 \mathrm{mg} \mathrm{L}^{-1}$.

\subsection{Characterization of obtained adsorbents}

The chemical compositions of raw material and of selected adsorbents are listed in Table 2. The calcined MK consists mainly of silicon and aluminium, whereas calcium, titanium and iron are present as impurities. Composition of FS after calcination is consistent with calcium mineral and XRD patterns show that it is in form of calcite. Loss of ignition of the raw materials is less than $5 \%$ indicating an almost complete calcination.

Crystalline phases in the adsorbents and the raw materials were identified by XRD. The obtained geopolymers showed amorphous structure represented by a broad amorphous halo at $20-30^{\circ}$, but small amounts of crystalline phases such as quartz, hematite, calcite and albite were also detected. Quartz and calcite peaks were sharp and the intensities were relatively strong, indicating that these species are the major crystalline components of the prepared composites along amorphous phases. In general, only intensity differences within the series of geopolymer composites were observed, but peak positions and phases remained constant. The presence of crystalline alumina phases was not identified.

Table 2: Chemical compositions of the raw materials and the prepared geopolymer composites.

\begin{tabular}{|l|l|l|l|l|l|l|l|l|}
\hline \multirow{2}{*}{ Constituent Content (wt. \%) } \\
\cline { 2 - 10 } & $\mathrm{Na}_{2} \mathrm{O}$ & $\mathrm{Al}_{2} \mathrm{O}_{3}$ & $\mathrm{SiO}_{2}$ & $\mathrm{MgO}$ & $\mathrm{CaO}$ & $\mathrm{Fe}_{2} \mathrm{O}_{3}$ & $\mathrm{Ti}$ & $\mathrm{SO}_{3}$ \\
\hline Metakaolin (MK) & 5.06 & 16.93 & 45.24 & 0.02 & 0.75 & 2.27 & 0.39 & 0.03 \\
\hline Fiber Sludge (FS) & 0.04 & 6.02 & 6.63 & 1.92 & 77.73 & 0.34 & 0.08 & 0.19 \\
\hline Blast furnace slag (BFS) & 0.03 & 6.07 & 28.49 & 5.59 & 33.39 & 0.56 & 1.01 & 0.85 \\
\hline 8BFSMK6040 & 8.01 & 11.92 & 36.58 & 0.01 & 12.43 & 1.66 & 0.63 & 0.88 \\
\hline 8FSMK2080 & 2.76 & 14.05 & 38.73 & 0.02 & 13.84 & 2.06 & 0.38 & 0.03 \\
\hline
\end{tabular}

\subsection{Influence of admixture content, initial ion concentration, mutual presence, and adsorbent dose}

The effect of initial concentration of target ions on ammonium and phosphate adsorption is measured by varying the concentration of ammonium solution from 10 to $200 \mathrm{mg} \mathrm{L}^{-1}$ and phosphate solution from 10 to $100 \mathrm{mg} \mathrm{L}^{-1}$, at initial $\mathrm{pH} 7.1$. In the first step, solutions contained only either ammonium or only phosphate ions were tested. In ammonium removal tests, $50 \mathrm{mg} \mathrm{L}^{-1}$ of ammonium was removed effectively with an adsorbent dose of $2 \mathrm{~g} \mathrm{~L}^{-1} 8$ BFSMK6040, reaching $23 \pm 3 \%$ removal $\left(4.3 \mathrm{mg} \mathrm{g}^{-1}\right)$ at final $\mathrm{pH}$ 7.9. At the same adsorbent dose 8FSMK2080 removed only $12 \pm 2 \%$. With increasing adsorbent dose to $5 \mathrm{~g} \mathrm{~L}^{-1}$, the removal up to $38 \pm 2 \%$ and $21 \pm 2 \%$ could be achieved for 8BFSMK6040 and 8FSMK2080, respectively. An 80 min contact time was enough for both geopolymer composites to reach saturation. According to Luukkonen [6], geopolymer containing only metakaolin has an ammonium removal capacity $6.5 \mathrm{mg} \mathrm{g}^{-1}$ at $50 \mathrm{mg} \mathrm{L}^{-1}$ initial concentration of ammonium nitrogen. Thus, an adsorption potential of the obtained composite 8BFSMK6040 is satisfactory.

In phosphate removal tests, the removal rate was $96 \pm 3 \%$ at 8 BFSMK6040 adsorbent dose of $2 \mathrm{~g} \mathrm{~L}^{-1}$ and phosphate concentration $10 \mathrm{mg} \mathrm{L}^{-1}$ and decreased to $68 \pm 2 \%$ for phosphate concentration of $100 \mathrm{mg} \mathrm{L}^{-1}$. The composite 8 FSMK2080 showed lower phosphate removal ability, as $60 \pm 2 \%$ of phosphate was adsorbed when phosphate concentration was $10 \mathrm{mg}$ $\mathrm{L}^{-1}$. Removal does not exceed $30 \%$ at phosphate concentration of $100 \mathrm{mg} \mathrm{L}^{-1}$. The removal efficiency increases with a smaller slope for adsorbent dose from $1 \mathrm{~g} \mathrm{~L}^{-1}$ to $10 \mathrm{~g} \mathrm{~L}^{-1}$. The adsorption was quantitative (>95\%) when an adsorbent doses were $2 \mathrm{~g} \mathrm{~L}^{-1}$ and $10 \mathrm{~g} \mathrm{~L}^{-1}$ at phosphate concentration $10 \mathrm{mg} \mathrm{L}^{-1}$ for 8BFSMK6040 and 8FSMK208, respectively. In contrast 
with ammonium adsorption, the uptake of phosphate ions by both composites was slow, and constant adsorption rates were achieved after $7 \mathrm{~h}$ for 8BFSMK6040 and 22h for 8FSMK2080.
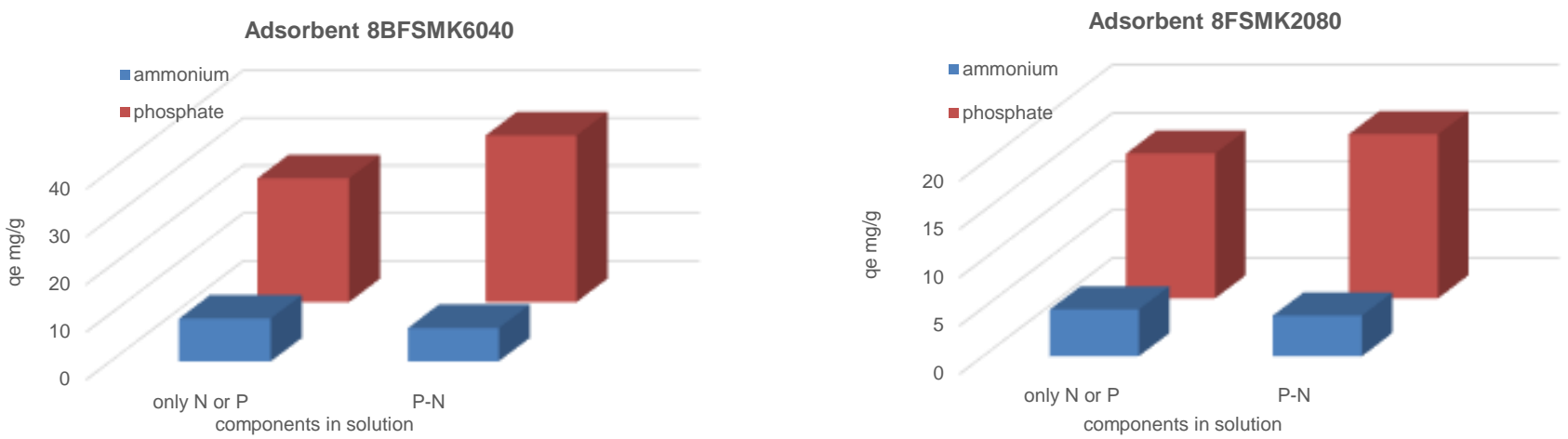

Fig. 1: Effect of the mutual presence of phosphate and ammonium ions on maximum capacities for geopolymer adsorbents 8BFSMK6040 (left) and 8FSMK2080 (right).

In mixture solution containing both ammonium and phosphate, the ammonium adsorption capacity onto the tested geopolymer composites declined insignificantly with increasing phosphate concentration. The maximum phosphate adsorption capacity was enhanced in the presence of ammonium for both composites (Fig.1). For 8BFSMK6040, the maximum capacity towards the phosphate in presence of both ions amounted to $35 \mathrm{mg} \mathrm{g}^{-1}$ as phosphate, while the maximum capacity in absence of ammonium was $26 \mathrm{mg} \mathrm{g}^{-1}$ as phosphate.

\section{Conclusion}

In this study, two geopolymer composites were developed and tested as an adsorptive media for the simultaneous removal of phosphate and ammonium. At slightly alkaline conditions (pH 7.6-8.1), the removal rates for both adsorbents towards phosphate ions were high (>86\% at adsorbent dose $5 \mathrm{~g} / \mathrm{L})$, whereas the ammonium removal up to $35 \%$ and $20 \%$ were achieved for 8BFSMK6040 and 8FSMK2080, respectively. The adsorbents enriched with nitrogen and phosphorus have a great potential to be recovered and reused as a fertilizer.

\section{Acknowledgements}

This study was conducted as part of the WaterPro project (project number A74635), funded mainly by the European Regional Development Fund (EAKR, Keski-Pohjanmaan Liitto/Kainuun Liitto). The authors wish to thank Mrs. Eeva Seppänen and Mrs. Marjukka Hyyryläinen for assisting with the laboratory work and analyses.

\section{References}

[1] S. R. Carpenter, N. F. Caraco, D. L. Correll, R. W. Howarth, A. N. Sharpley, and V. H. Smith, "Nonpoint Pollution of Surface Waters with Phosphorus and Nitrogen," Ecol. Appl., vol. 8, no. 3, pp. 559-568, 1998.

[2] D. Bergero et al., "Ammonia removal capacity of European natural zeolite tuffs: Application to aquaculture waste water," Aquac. Res., vol. 25, pp. 813-821, 1994.

[3] M. P. Bernal and J. M. Lopez-Real, "Natural zeolites and sepiolite as ammonium and ammonia adsorbent materials," Bioresour. Technol., vol. 43, no. 1, pp. 27-33, 1993.

[4] D. Guaya, C. Valderrama, A. Farran, C. Armijos, and J. L. Cortina, "Simultaneous phosphate and ammonium removal from aqueous solution by a hydrated aluminum oxide modified natural zeolite," Chem. Eng. J., vol. 271, pp. 204-213, 2015.

[5] L. Lin, C. Wan, D.-J. Lee, Z. Lei, and X. Liu, "Ammonium assists orthophosphate removal from high-strength wastewaters by natural zeolite," Sep. Purif. Technol., vol. 133, pp. 351-356, 2014.

[6] T. Luukkonen et al., "Optimization of the metakaolin geopolymer preparation for maximized ammonium adsorption capacity,” J. Mater. Sci., vol. 52, no. 16, pp. 9363-9376, 2017. 
[7] T. Luukkonen et al., "Removal of ammonium from municipal wastewater with powdered and granulated metakaolin geopolymer," Environ. Technol., vol. 39, no. 4, pp. 414-423, 2018. 